\title{
Analysis of Innovation, Innovative Thinking and Innovative Methods
}

\author{
Decheng Yang ${ }^{1, *}$ Xingwei Sun ${ }^{1}$ Fuquan $\mathrm{Cao}^{1}$ Fengcheng $\mathrm{Qu}^{1}$ \\ ${ }^{1}$ Heihe University, Heihe, Heilongjiang, China \\ *Corresponding author. Email: hhxytriz@163.com
}

\begin{abstract}
The innovation ability is the essential core ability in the face of various competitions and challenges in the information age with rapid development and change, and innovative thinking is at the core of the innovation ability. This paper puts forward the T-shaped structure of innovative thinking and constructs the system structure of innovation ability. The first step to innovation is to break the conventional thinking. It is necessary to have a correct understanding of conventional thinking, guide innovative thinking through innovative methods and rein innovative methods by innovative thinking, so as to break the mystique of innovation and build the confidence to innovate. It is an effective way of grasping and excavating the thinking potential and enhancing the innovation ability to understand the potential of the brain and its general development, and form the habit of positive thinking through constant practice.
\end{abstract}

Keywords: Innovation, Innovative thinking, Innovative method, T-shaped thinking, Innovative course.

\section{INTRODUCTION}

The quality of thinking determines the quality of the future. The essence of traditional thinking is to clear away false, confusing and erroneous assumptions rather than to propose better ideas and methods. Its shortcoming is that it cannot adapt to change. In today's fast-changing world, "change" has increasingly become an important attribute of thinking. The value of education is not only reflected in students' knowledge mastery, but also in the development of students' thinking [1]. The important thing about the future is not to judge what it is, but to think about what it could be. Innovative thinking is needed!

The famous educator Tao Xingzhi once said, "Creation can be made anywhere and anytime by anyone." The essence of "creation" is "innovation",

*Fund: Higher Education Teaching Reform Research Project of Heilongjiang Provincial Education Department in 2020 "Construction of Innovative Thinking and Method Curriculum System for Science and Technology Majors in Colleges and Universities Based on TRIZ" (Project No. SJGY20200485).

The key project of Heilongjiang Provincial Education Science Planning in 2021 "Research on the Improvement of College Students' Innovative Thinking Ability Based on STRIZ" (Project No.: GJB1421623). which is a process in which people produce new knowledge or new things through innovative thinking and behavior and innovative thinking plays a leading role. Creative thinking exists in everyone and sparks inspiration all the time. It is these sparks that guide mankind from ignorance to civilization, from the primitive times to today's developed science and technology and brilliant culture...

Innovation determines the comprehensive strength and competitiveness of a country and a nation [2]. On November 29, 2012, when visiting the exhibition "The Road to Revival", General Secretary Xi Jinping pointed out: "Everyone has ideals and pursuits, and their own dreams. Now, many people are talking about the Chinese dream. I believe that to realize the great rejuvenation of the Chinese nation is the greatest dream of the Chinese nation since modern times. Now, we are closer to the goal of great rejuvenation of the Chinese nation than at any time in history, and more confident and capable of realizing this goal than at any time in history." Today's fast-developing China has brought unprecedented opportunities to me and to all of us. It can be said that we are closer to our dreams than ever before. And the best way to realize the "Chinese dream" and "my dream" is innovation. 


\section{INNOVATION AND INNOVATIVE THINKING}

What is innovation? Do we need to innovate? Is innovation distant and illusive or concrete and can happen to all sometimes? In fact, innovation is all around people all the time, neither far away nor mysterious, and it is very close to each individual.

\subsection{Innovation}

The word "innovation" comes from Latin and originally had three meanings: to renew, to create something new, and to change. According to the "Modern Chinese Dictionary", innovation is to throw away the old and create the new. Innovation refers to the behavior of offering ideas that are different from conventional or normal thinking under existing thinking mode, improving or creating things, methods, elements, paths and environments that do not exist or are not perfect and can obtain certain beneficial effects by using the existing knowledge and materials in a specific environment, in line with the ideal needs or to meet the social needs, and the behavior can obtain certain beneficial effect. Innovation is a unique cognitive and practical ability of human beings, and a highlevel expression of human subjective initiative. It is a conceptualization process characterized by new thinking, new invention and new description.

Innovation has always promoted the progress of human society. From the point of view of archaeology, human beings have been in this planet for six million years since their birth. About 2.5 million years ago, humans walked from trees to land, learned to use tools, and then learned to use fire, make pottery, produced language, invented characters... The history of human development and progress is a history of innovation as it were. In the 200 years since the First Industrial Revolution, in particular, innovation has brought tremendous changes to human life. Today, the Internet age, with computer technology at its core, has greatly expanded people's perceptions and changed the lifestyles and habits — people can no longer imagine what life would be like without the Internet.

\subsection{Innovative Thinking}

Innovative thinking has unique characteristics distinguishing it from general thinking, which are the four basic characteristics of innovative thinking: pioneering, having staged features, comprehensibility and plasticity [3]. Innovative thinking refers to the thinking process of solving problems in novel and original ways, which is not restricted by existing conventional thinking. Through this kind of thinking, people can break through the boundary of conventional thinking, think about problems with methods and perspectives that are unconventional or are even against the grain, and put forward unique solutions, so as to produce novel, unique and socially meaningful thinking results. As is often said, "Thinking determines the way out, the vision determines the outcome". Innovative thinking is an important prerequisite to realize innovation.

\subsection{Correct Understanding of Conventional Thinking}

Human thinking is a complex psychological phenomenon, an indirect and general reflection of human brain to the objective reality, and a highlevel form of cognition. It reflects the essential attribute of objective things and the relation of the regularity. People's thinking is often based on experience. Because children do not have too many shackles of experience, their thinking has broad free space - children's imagination is rich, naive, and even ridiculous. With the increase of age and experience, "solidified" impressions of things will be gradually formed, and the "common" things will be judged by past experience. While this allows people to take most of the things in daily life in stride, it creates a barrier to innovation as there is little positive thinking involved. Thinking set [4] refers to fixed thinking mode. When people form a thinking set, they will restrict the development of their own thinking and it is difficult to form innovative thinking. Conventional thinking is the experience accumulated by people through continuous learning and practice and the law and way of forming their own unique understanding and cognition of the world and the objective, so it has obvious individuality.

Conventional thinking is a way of thinking that deals with problems in a conventional way. When conditions remain unchanged, people can quickly perceive things in the real environment and make the right response, which can promote people to better adapt to the environment. But conventional thinking is not conducive to innovative thinking, cannot adapt to changing conditions, and is not conducive to creation. 


\subsubsection{The Positive Effect of Conventional Thinking}

In problem solving activities, the positive role of conventional thinking lies in thinking of similar problems that have been solved according to the problems solved, comparing the characteristics of the new problems with the old ones, relating existing knowledge and experience to the current problem situation through the common features of the old and new problems, tackling a new problem using the knowledge and experience of dealing with a similar old problem, or transforming the new problem into a familiar problem that has been solved, so as to prepare positively for the new problem to be solved. Conventional thinking can save people a lot of groping and testing steps, shorten thinking time and improve efficiency. In daily life, conventional thinking can help people solve more than $90 \%$ of the problems encountered every day.

\subsubsection{The Negative Effect of Conventional Thinking}

Conventional thinking has both positive and negative effects on problem solving. It easily makes people develop ideological inertia, and form a rigid, mechanical, stereotyped habit of solving problems. When the old and new problems are similar in shape and different in quality, conventional thinking often lead the problem solver into a misunderstanding. A large number of cases show that conventional thinking does have a great negative impact on problem solving. When the conditions of a problem change qualitatively, the conventional thinking will make the problem solver stuck in a rut, feel hard to get new thinking and make new decisions, resulting in the negative transfer of knowledge and experience.

According to materialist dialectics, there are similarities and differences between different things. Conventional thinking emphasizes the similarity and invariance between things. In the process of problem solving, it is a thinking strategy of "coping with shifting events by sticking to a fundamental principle ". Therefore, when the similarity of the new problem is dominant compared with the old problem, the conventional thinking formed by the solution of the old problem is often conducive to the solution of the new problem. When the difference between the new problem and the old problem is dominant, however, it often hinders the solution of the new problem.
From the perspective of the cortical activity of the thinking process, the influence of inertia is a kind of habitual neural connection, that is, the previous thinking activity has a guiding influence on the next thinking activity. Therefore, when two thinking activities are of the same nature, the former thinking activity will play a correct role in guiding the latter. Yet when the two thinking activities are of different natures, the former thinking activity will produce a wrong guidance to the later.

\subsection{Misunderstanding}

There are some misconceptions about innovation. First, innovation is unreachable. This conception holds that innovation is the patent of a few smart people, innovation means high-tech, subversive innovation and innovation needs advanced professional knowledge and innovation ability, as well as huge investment. Second, innovation is none of their business. Such a thought holds that innovation is for research universities, and ordinary universities do not need innovation, and that the elite makes innovation, entrepreneurs seek entrepreneurship, and I only care about employment. Third, innovation courses are difficult. This belief holds that teachers need to be very familiar with innovation theories and practice, which is difficult to be combined with professional knowledge and skills, and the teaching effect of the course will not be very ideal.

\section{INNOVATIVE THINKING AND INNOVATIVE METHODS}

As General Secretary Xi Jinping once pointed out, "Throughout the history of human development, innovation has always been an important principle for the development of a country and a nation, and an important force for the progress of human society." One of the earliest methods of innovation used by humans is trial and error, which requires a lot of trials and errors before a satisfactory answer is reached. The times of trials and errors depends on the knowledge and experience of the designer. The so-called innovation is the work of a few geniuses, which is an experience drawn from trial and error. The effectiveness of the choice depends on the complexity of the task. The degree of difficulty can be determined by the number of tests, which must be done in order to obtain a guaranteed result - to solve the problem. Invention history shows that this number can vary widely, from dozens of trials for the simplest tasks to hundreds of thousands for the 
more complex ones. Trial and error is very effective when trying 10 or 20 solutions, but it can waste a lot of energy and time when solving more complex tasks.

In order to solve complex problems, people have invented many methods in a long period of innovative practice, such as brainstorming method, questioning method, problem listing method, combination method, information intersection method, form analysis method, association method, transplantation method, reverse method, value enhancement and value reduction method, method of focal objects, Six Hat Thinking, six sigma $(6 \sigma)$, Quality Function Deployment (QFD), Theory of Inventive Problem Solving [5] (TRIZ) and so on. Some of these methods are directly guided thinking, some are based on quality management, some are based on requirements transformation, and some are applied to technical invention. So, what is the relationship between these innovative methods and innovative thinking?

\subsection{Guiding Innovative Methods with Innovative Thinking}

Thinking needs a scientific method, which can determine the way of thinking, provide the route of thinking, and improve the efficiency and quality of thinking. For example, Six Hat Thinking [6] provides a method of "parallel thinking", which can restrain participants to think in the same way at the same time in the process of team innovation, so as to effectively avoid arguments and improve thinking efficiency; based on evolution and dialectics, TRIZ provides a series of tools and methods for solving technical problems, which holds that at the beginning of problem solving, idealized method should be applied to determine the final ideal solution, so as to solve the problem toward the correct direction of the goal to avoid blindness, and then the obstacles leading to the ideal solution should be found through contradiction analysis to determine the original understanding, and finally to find the best way to solve the problem through the resource analysis.

\subsection{Applying Innovative Methods with Innovative Thinking}

In the whole process of innovation, thinking plays a leading role, while innovation methods and tools play the role of "auxiliary" thinking. Thinking is the leader of innovation, the soul of the method, and the "internal skills" that should always be practiced by innovators. Only when the innovative thinking is understood deeply and melted into consciousness and becomes habits, the process of innovation can go its way smoothly. Tools are the means of innovation, the basis of methods, and the "techniques" that innovators should strive to master. For example, the brainstorming method can "assist" the users to carry out collective "wild thinking" to fully stimulate their imagination and ideas, and the direction of thinking and the generation of ideas still depend on the participants' thinking; the Nine Screen Method (from TRIZ) can help users to establish a comprehensive understanding of things in both time and space dimensions, but if there is no evolutionary, dynamic and vivid innovative thinking to control the application process and route, it is difficult to achieve the desired effect.

\subsection{Using Whole Brain Thinking}

In general, people's thinking is based on previous knowledge, experience and rational judgment, and is often limited by linear logical thinking. As a result, people generally focus on the "why" rather than the "what could it be". This kind of traditional thinking is vertical thinking from top to bottom in a fixed range according to a certain thinking line, and cannot escape the fetters of the original thinking framework (conventional thinking), so creative thinking cannot be realized. It is called "vertical thinking", also known as "vertical thinking method". Lateral thinking is to get rid of the existing knowledge and old experience constraints when thinking about problems, break through the routine, and put forward creative opinions, viewpoints and programs. Different from vertical thinking, lateral thinking considers not the certainty of things, but the possibility of its multiple choices; it's not about perfecting old ideas, but about coming up with new ones; it is not just the pursuit of correctness, but the pursuit of richness. Generally speaking, innovative thinking belongs to the whole brain thinking, which belongs to the $\mathrm{T}$ shaped thinking structure, including both horizontal divergence and vertical convergence, as shown in "Figure 1". 


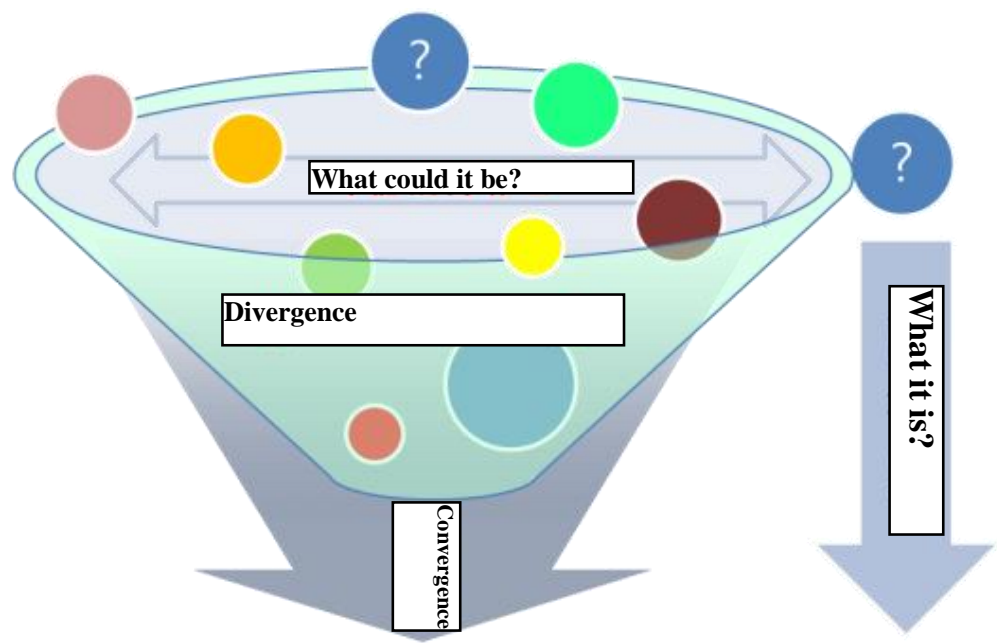

Figure 1 T-shaped structure of innovative thinking.

The functions of the brain can never be simply divided into left and right. Between the two hemispheres of the brain are 250 million nerve fibers in a "high-speed information channel" that constantly transmits vast amounts of information to each other. Although the two hemispheres "do different things", they are functional in all areas, and each neural activity mind is scattered throughout the brain, and the two hemispheres complement each other to form "decisions". What distinguishes the two hemispheres more than their locations is the nuance of how they work. The reason for the emphasis on stimulating the right brain is that in the course of education and development, rational thinking gradually takes the upper hand. The inertia formed by thinking experience also makes people learn to stick to rules, slowly eroding the vitality of imagination. While this works well for everyday life and work, it is bad for innovation.

The process of creative problem solving is a dialectical and dynamic process, and the level of thinking determines the level of tool application. Innovation ability comes from the organic combination of innovative thinking, innovative methods and innovative practices. Thinking guides tools and tools assist thinking, and the interaction between the two forms a method; methods can only breed skills after continuous application and deep understanding in practice; and abilities can only be obtained with a grasp of methods and skills, as shown in "Figure 2".

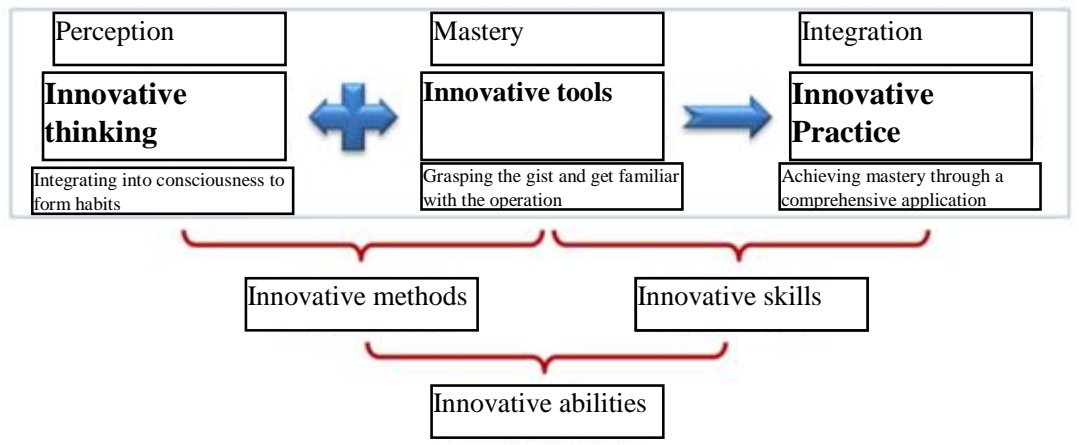

Figure 2 Structure chart of innovation ability.

\section{CONCLUSION}

The innovative thinking method is the thinking method that dares to break the conventional thinking, emancipate the mind, surpasses the old conventions, adapt measures to the current conditions, keep pace with the times, and opens the new situation of work with the new leap of thinking 
and understanding. The human brain has limitless potential, but the precondition of giving play to this potential is to use it properly. When people keep a healthy and confident state of mind, understand the true association of innovative thinking, master the right way of thinking, and think sharp by use of full "positive energy", their inspiration will flow and talent will emerge.

\section{AUTHORS' CONTRIBUTIONS}

Decheng Yang is responsible for experimental design, Xingwei Sun contributed to revising and editing, Fuquan Cao contributed to revising and editing, Fengcheng Qu contributed to revising and editing.

\section{REFERENCES}

[1] Qian Yingyi. Educating Students in Critical Thinking and Creative Thinking: Theory and Practice [J]. Tsinghua Journal of Education, 2018, 39(04): 1-16. (in Chinese)

[2] Zhu Yongxin, Yang Shubing. An Outline of Innovative Education [J]. Educational Research, 1999(08): 8-15. (in Chinese)

[3] Li Ge. Research on the Mechanism of Brainphysiological and Psychosocial Cooperation of Innovative Thinking [D]. Jilin University, 2020. (in Chinese)

[4] Jiang Yun. Training of Innovative Thinking Ability of TV Journalists in New Media Era [J]. Research on Communication Power, 2020, 4(08): 98-99. (in Chinese)

[5] Jiang Yun. Training of Innovative Thinking Ability of TV Journalists in New Media Era [J]. Research on Communication Power, 2020, 4(08): 98-99. (in Chinese)

[6] Cao Fuquan. Guide to Approaches to Creative Thinking [M]. Heilongjiang Education Press, 2009. (in Chinese)

[7] Edouard de Bono. Parallel Thinking Unscramble the Deep Value of Six Thinking Hats [M]. Wang Yi Trans. Beijing: Enterprise Management Publishing House, 2004. 